\title{
13
}

\section{AUGMENTED REALITY AS NEWS}

\author{
Pasi Ikonen and Turo Uskali
}

If you are building complex, expensive VR today for the limited number of people, who get VR headsets, and [are] willing to scratch up on their heads to have the experience, experimentation is great, nice, but [...] I think augmented reality is actually more interesting and has more potential for news.

A manager of a big tech company 2016

This quotation is from an expert interviewed during the Global Editors Network's summit in Vienna in June 2016. A management-level employee of a big tech company, who asked for anonymity, criticized the hype around virtual reality (VR) and predicted that actually augmented reality might serve journalism better thanVR. Indeed, following the VR chapters in this volume, it is time to direct our attention to the implications of augmented reality (AR). In this chapter we introduce the AR concept, provide a brief history, and finally focus on the use of AR in journalism and other productions.

In $\mathrm{AR}$, virtual information or objects are added to the otherwise real environment. Comparing VR, AR, and mixed reality displays, Milgram and Kishino (1994, 4) defined AR as "any case in which an otherwise real environment is 'augmented' by means of virtual (computer graphic) objects". Ronald Azuma added the attribute of real time to the definition, requiring that $\mathrm{AR}$ combines real and virtual, is interactive in real time, and is registered in three dimensions (Azuma 1997).

AR history goes way beyond Snapchat filters from 2015 and the worldwide success of Pokémon Go in 2016. One groundbreaking experiment in the field included "The Sword of Damocles" from 1968, the first-known head-mounted display (HMD), created by Ivan Sutherland and Bob Sproull (Kipper \& Rampolla 2013). The history of AR research in the United States (US) also stretches back to the 1970s and 1980s (Feiner 2002).

In 1990 Boeing engineers Tom Caudell and David Mizell designed an HMD system that provided wiring instructions for airplanes (Berryman 2012). More 
importantly, they later coined the term Augmented Reality in a 1992 conference paper (Caudell \& Mizell 1992).

By 1997 AR had been applied or tested at least in medical visualization, maintenance and repair, annotation, robot path-planning, entertainment, and military aircraft navigation and targeting (Azuma 1997). Furthermore, by 2012, Kipper and Rampolla (2013) also listed advertising, task support, navigation, home, industry, art, sightseeing, gaming, social networking, education, and translation as areas of use for AR.

The superimposed virtual elements can be viewed and interacted with 1) wearable HMDs such as AR glasses, 2) a smartphone, tablet, or personal computer with a webcam, or 3) via a spatial display such as a window, projector, or a specially designed room (Kipper \& Rampolla 2013). AR applications can either add more information to the user's perception of the current physical reality (e.g. cafeteria recommendations when walking in the city) or create an artificial environment where the user is (e.g. virtual furniture in the user's home). AR can base its tracking on markers, such as shapes and images, or a location, e.g. the Global Positioning System (GPS) (Kipper \& Rampolla 2013).

\section{The technology: smartphones, smart glasses, and authoring tools}

The user of one of today's visual displays can easily make solid objects transparent - he can "see through matter!"

Ivan Sutherland 1965

Currently in 2019 smartphones are by far the most popular means of using AR, although AR was not originally designed for mobile phone use (Pavlik \& Bridges 2013). HMD and smart glasses also have AR storytelling potential.

The first AR product to generate massive hype was Google Glass, prototyped in 2013 and publicly released in 2014. The sales of the much-criticized glasses were halted in 2015 (Langley 2018). In other words, it flopped. There were particularly serious privacy concerns (Cave 2015; Levy 2017). Since 2017, the company X (a subsidiary of Alphabet Inc.) has been selling Glass Enterprise Edition for its partners (Kothari 2017). Microsoft released HoloLens in 2016 and HoloLens 2 in 2019 (Bohn 2019). Many other companies are introducing their own products (see e.g. eMacula 2019; Heaney 2019; Statt 2019). For example, since August 2018, consumers have been able to acquire the much-hyped Magic Leap One glasses (Swider \& Fitzsimmons 2019). In recent years smart glasses' prices have come down, and one can acquire the cheapest ones for a few hundred US dollars, whereas the enterprise version of HoloLens 2 was priced at around $\$ 3,500$ in 2019 (Bohn 2019).

Producers need an authoring tool to create AR applications. Tools are made for both programmers and non-programmers (Schmalstieg, Langlotz \& Billinghurst 2011). Wikitude, the first web browser for AR, was launched in 2008 (Hauser 
2010). Early AR tools used by media companies included Junaio (later purchased by Apple) and Aurasma (Pavlik \& Bridges 2013). Both Google (ARCore) and Apple (ARKit) released their own platforms for building AR experiences in 2017 (Allum et al. 2018), and they are being used, for example, by The New York Times (The New York Times 2019). Facebook has its own AR platform called Spark AR (previously Camera Effects Platform) that helps developers build apps for the social networking platform (Spark AR 2018).

\section{The evolution of AR in journalism}

Azuma (2015) sees storytelling as one of the most important ways to utilize augmented and mixed reality. John Pavlik and Frank Bridges see AR as serving the same function as news: "it augments the user's experience with the real-world, natural environment” (Pavlik \& Bridges 2013, 6).

One can argue that sports broadcasts paved the way for AR in journalism. AR has been used in sports at least since 1998, when Sportvision broadcast the first virtual yellow first down marker during a live American football National Football League (NFL) game (Augment.com 2016). These real-time virtual lines, visible to TV audiences, have been used since then in many other sports events, such as athletics and swimming, to indicate record times or target levels.

Newsrooms started experimenting around 2010 with AR technology using printed paper extensions and Quick Response (QR) codes. Esquire magazine created a cover and a few articles for their November 2009 issue that could be augmented with a mobile app (Esquire magazine 2009; Pavlik \& Bridges 2013). In a similar vein, augmenting Süddeutsche Zeitung's SZ magazine in 2010, users could watch videos using the mobile app Metaio (O'Hear 2010). The New York Times Magazine used a QR code on its $10^{\text {th }}$ anniversary special cover in 2010 to link users to short video clips (Pavlik \& Bridges 2013). Some early examples were various companies that targeted children (The Hamilton Spectator 2016; Baluja 2013), experimented with AR advertising (The Guardian 2012), and created a locationbased experience (Valcarce, Bolós, \& Recio 2017). Similar extensions to print products have been produced around the world. Table 13.1 lists early print AR extensions from different countries.

Smaller news outlets have rarely tried out AR. In a 2017 survey for local newsrooms in the US, none of the respondents reported using AR (Radcliffe, Ali \& Donald 2017), despite the fact that researchers had found some evidence of AR productions. For example, The Herald and News in Klamath Falls, Oregon, has experimented with AR since 2015 (Radcliffe, Ali \& Donald 2017). The same report hinted at newsrooms' modest interest in learning about AR technology.

From 2016 onwards, AR journalism applications have mostly used 3D models, location-based stories, and augmented studios. Big media outlets in the US have led this development. In some rare cases, smart glasses have been utilized, and AR has occasionally been also used as a reporting tool. We now look at some of the most prominent examples. 
TABLE 13.1 Examples of printed paper AR extensions from different countries.

\begin{tabular}{|c|c|c|}
\hline Country & $\begin{array}{l}\text { Publisher/magazine/newspaper } \mathcal{E} \\
\text { year of publication }\end{array}$ & Reference \\
\hline Canada & $\begin{array}{l}\text { Glacier Media: } 12 \text { newspapers } \\
\quad \text { in } 2013 \\
\text { Toronto Star } 2013 \\
\text { Winnipeg Free Press } 2013 \\
\text { The Hamilton Spectator } 2016\end{array}$ & $\begin{array}{l}\text { (Layar 2013) } \\
\text { (Emrich 2013; Baluja 2013) } \\
\text { (Hamilton Spectator 2016) }\end{array}$ \\
\hline Germany & $\begin{array}{l}\text { SZ magazine } 2010 \\
\text { Stern } 2011 \\
\text { Welt der Wunder } 2011 \\
\text { Auto Bild } 2015 \\
\text { Rheinische Post } 2015\end{array}$ & $\begin{array}{l}\text { (O'Hear 2010) } \\
\text { (Raso et al. 2016) }\end{array}$ \\
\hline India & $\begin{array}{l}\text { Mid-Day: QR code } 2010 \\
\text { Times of India } 2012 \\
\text { Dainik Bhaskar } 2016\end{array}$ & $\begin{array}{l}\text { (Pahwa 2010) } \\
\text { (Chaudhary 2012) } \\
\text { (Goyal 2016) }\end{array}$ \\
\hline Japan & Tokyo Shimbun 2013 & (Baluja 2013) \\
\hline Malaysia & The Star: iSnap 2012 & (Mahpar \& Mahalingam 2012) \\
\hline Spain & $\begin{array}{l}\text { Fotogramas magazine: QR code } \\
\quad 2010\end{array}$ & (Valcarce, Bolós \& Recio 2017) \\
\hline United Kingdom & $\begin{array}{l}\text { The Guardian: AR advertising } 2012 \\
\text { The Times } 2013 \\
\text { The Telegraph } 2013 \\
\text { The Independent } 2013 \\
\text { Talk About Local } 2013\end{array}$ & $\begin{array}{l}\text { (The Guardian 2012) } \\
\text { (Witkin 2013) } \\
\text { (Press Gazette 2013) }\end{array}$ \\
\hline United States & $\begin{array}{l}\text { Esquire magazine } 2009 \\
\text { The New York Times Magazine: } \\
\text { QR code } 2010 \\
\text { Boston Globe Winter Arts Guide } \\
2011\end{array}$ & $\begin{array}{l}\text { (Esquire magazine 2009) } \\
\text { (Pavlik \& Bridges 2013) } \\
\text { (Kieslow 2011) }\end{array}$ \\
\hline
\end{tabular}

When using 3D models for AR, graphics are superimposed over the user's real environment via a smartphone app. The Washington Post first used AR in May 2016, when they published a story on the arrest and death of Freddie Gray in Baltimore, using narrated scenes with 3D models for their app (WashPostPR 2016). They continued with a series on architecture (Moses 2017). Quartz updated their iPhone app with AR capabilities in September 2017, bringing to life, for example, the Cassini-Huygens spacecraft, the Roland TR-808 drum machine and the Berlin Wall (Southern 2017). The New York Times released their first AR production for mobile phone in February 2018, centered on the PyeongChang Winter Olympics and sponsored by Ralph Lauren (Branch 2018). A different perspective was given by the Tham Luang Cave story, also at The New York Times: it brought to the user's environment models of the small openings of the cave where 13 members of a youth soccer team were trapped in 2018 (Beech 2018). Australian Broadcasting Company (ABC) introduced a Space Discovery app in May 2018 (Bazley 2018). 
Applications for AR glasses remain rare, as the technology has not yet become more common. CNN (Roettgers 2019) and Cheddar (Strange 2018) have released news applications for the Magic Leap One AR glasses, allowing users to pin regular 2D news videos to the walls and ceilings of their real environment.

Similarly to how sports broadcasts have employed AR, television studios can be augmented too. In May 2018, ABC News in the United States produced an augmented news report on air about the British royal wedding with $3 \mathrm{D}$ models brought to the studio (ABC News 2018), and they had an AR studio for the US midterm elections (Jacobson 2018). Al Jazeera has also built AR studios to cover the Winter Olympics 2018 (Hill 2018a) and provide a tour of Jerusalem (Hill 2018b), among other topics.

One of the most active news outlets to augment studios has been The Weather Channel (together with the Future Group). They have used AR in weather forecasts since summer 2018 (LaForme 2018). The company has planned to produce 80 percent of its programming using AR andVR by 2020, according to their Director of Weather Presentation in a Washington Post interview (Cappucci 2018). Their weather forecasts from 2018 and 2019 have portrayed a tornado that also seems to enter the studio and break it apart, a hurricane with rising water levels with the meteorologist standing next to the flood, and an ice storm that causes a bus to almost crash into the meteorologist situated in the middle of the scene.

These fact-based but obviously made-up animations bring about some ethical considerations. It should be considered how the forceful visualizations affect attention and whether they interfere with or direct viewers' attention toward the storms' facts and impacts. In addition, the relation between factual information and visual speculation calls for ethical discussion.

Besides speculative animations, AR does raise more general ethical issues in journalism. Fundamental public values, such as privacy (e.g. issues related to recording, face-recognition technology, and ownership of AR information) and balance of power (who sets the standards for technology?) touch upon AR (Royakkers et al. 2018). The physical appearance of technology can affect social situations, and sensor-based reality has an effect on privacy, security, and trust. Ethics should therefore be considered in the design and applied to the possible interventions needed, researchers argue (Mann et al. 2018). Use of smart glasses creates concerns about privacy, identity, autonomy, and ownership (Wolf, Grodzinsky, \& Miller 2016). AR also poses legal challenges (Lemley $\&$ Voloch 2017) that relate to privacy, marketing, intellectual property, real property, torts, personal injury, and criminal acts (Wassom 2014). Another ethical consideration is what topics are even suitable for AR (Kunova 2019).

What about harnessing AR technology as a reporting tool? The Hindustan Times employed Snapchat filters when Yusuf Omar interviewed underage survivors of rape. The filters, used during the interviews, helped to create anonymity and give a sense of security to the interviewees on the extremely sensitive topic (Scott 2016).

AR could also be used for crowdsourcing. One research paper found that AR could be applied in crowdsourcing processes to support its planning and 
crowdworkers' activity and for sharing and consuming location-based usergenerated content (Väätäjä et al. 2013).

News organizations continue experimenting with AR. Google News Initiative, the Knight Foundation and the Online Journalism Association gave out Journalism 360 Awards in December 2018. Three of the 11 winners included AR in their project descriptions: these relate to $3 \mathrm{D}$ assets, a spatialized audio editor, and AR prototypes for health and science news (Knight Foundation 2018).

\section{Future inspiration: other kinds of AR stories}

Overall, a huge selection of AR experiences and applications exists for devices accessible by ordinary consumers. As the examples in this chapter show, the technology itself holds many unexplored options for journalistic use. Creating locationbased features, crowdsourcing, and utilizing social networking in AR remain as such possibilities (Pavlik \& Bridges 2013).

Interestingly, research on user experiences of AR storytelling is still almost nonexistent. In one example, Fedorovskaya and Yu (2015) studied the preferences of 32 participants reading a short story (print or digital) with or without video augmentation. In their study, AR was found to enhance the overall experience. Overall, AR user experience has been studied in many contexts, however (see e.g. Dirin \& Laine 2018; Ko, Chang, \& Ji 2013; Siriborvornratanakul 2018; Zhou 2018).

Experimenting with augmenting another medium, Billinghurst, Kato, and Poupyrev introduced the augmented book, MagicBook, in 2000 (Billinghurst, Kato, \& Poupyrev 2001). It was a combined AR and VR experience, with the users holding a hand-held display, allowing for a simultaneous multi-user experience. Many augmented books have been seen since, for example the graphic novel Priya's Shakti from 2004 (Bosworth \& Sarah 2018).

The 2019 book by Melissa Bosworth and Lakshmi Sarah offers an excellent review of VR, mixed reality, and AR storytelling cases from recent years (Bosworth \& Sarah 2018). In addition, the Optimist issue of Time magazine in 2018 was augmented with videos, infographics, and animations, including narration from Bono and Bill Gates. Outthink Hidden, a production of The New York Times' T Brand Studio, offered location-based stories of remarkable but relatively unknown scientists. The user could place virtual statues in ten cities around the US and learn about the scientists' stories. Three of the experiences mentioned in Bosworth and Sarah's book were based on an exact location. "Hello, We're from the Internet" was an independent "guerilla" AR museum experience in 2018. Users could point their phones at paintings in the Museum of Modern Art in New York to see other artworks. "New Dimensions in Testimony" at Illinois Holocaust Museum (2017) is a very ambitious project in which holocaust survivors answered around 1,250 prerecorded questions. Viewers who see a hologram of the survivor in the museum theater can ask them any questions, while a natural-language processing system determines which answer the hologram will use. In "Terminal 3" (2018), created by Asad Malik, users put on Microsoft's HoloLens and saw an airport interview of a 
person selected based on racial screening. When finishing this experience, the users were instructed to go to the next room, where they met in real life the person they had just seen virtually (Bosworth \& Sarah 2018).

Robert Azuma has stressed the utility of location-based experiences, observing that they could make users view the world in a different way (Azuma 2015). Some early situated experiences offered an opportunity to experience narratives from different points of view. "Three Angry Men" from 2003 did this in a fictional setting, whereas "You Get Me" from 2008 used authentic stories of real people in London, and it was playable at the Royal Opera House in London. In "MR Sea Creatures" from 2005, a museum interior was transformed to be underneath the sea, with virtual ancient sea creatures brought to life. "The Westwood Experience" from 2010 combined a variety of MR effects with live actors and an authentic environment related to the story (Azuma 2015).

\section{AR storytelling types for journalism}

By reading through the AR academic literature and browsing news media websites, we have identified 11 different types of storytelling with AR (Table 13.2). The list is not a comprehensive account of AR cases around the world, but it gives an idea of what has been done in recent years.

Overall, the volume of AR productions has remained low, and smaller or medium-sized newsrooms have mostly stayed out of the whole business. Breaking and hard news may not be the optimal areas for producing AR journalism, whereas sports and travel might be more easily suited for it (Pavlik \& Bridges 2013).

We can argue that weather predictions and live sports events have led the way in the adaptation of AR in journalism globally. For example, sports programs in Finland focusing on the Winter Olympics and national ice hockey series have been at the forefront in adapting AR technologies. Both public broadcasters, such as the Finnish Broadcasting Company in 2018, and commercial broadcasting/ telecom companies, such as Telia TV in 2019, have utilized AR with live athlete holograms, bringing them to the TV studio from the sports event hundreds of kilometers away.

Producing AR usually requires careful planning, more time, and a bigger team than regular reporting. Use of the technology in TV began with colored lines augmented to sports broadcasts. Media organizations and newsrooms experimented with mobile AR at the beginning of the 2010s. Around the year 2018, applications using 3D models and studio augmentations became more frequent, many of these as collaborations with brands (see e.g. Moses 2017).

\section{Conclusion: still waiting for the AR breakthrough}

Nic Newman's study (2018) for the Reuters Institute for the Study of Journalism predicted a breakthrough year for mobile AR in 2018, but "killer apps" in AR journalism are still to be seen. 
TABLE 13.2 Types of AR storytelling for journalism.

Type of AR storytelling
Situated documentary
Localized guides
Localized news
Augmented elements
in a TV studio or
broadcast

Platforms/devices used mounted display, and a tablet as part of a user interface (early examples)

Smartphone Head-mounted display

Smartphone app

Smartphone app

TV/web

Physical

Examples

environment location 2013)

Studio
Backpack, a head-
In a specific Columbia University location campus Touring Machine (Höllerer, Feiner \& Pavlik 1999)
110stories (110stories 2019)

In a specific Stella Artois: Le Bar Guide location (Hannaford 2009)

In a specific Talk About Local (Witkin

The Weather Channel (LaForme 2018)

CNN: Super Bowl (Egripment 2018)

ABC News: Royal Wedding (ABC News 2018)
Augmented live event
Printed paper QR code link
Printed paper AR extension providing images, video and links

Smartphone app

Smartphone app

\section{Virtual objects superimposed on the user's environment}

Smartphone app

Printed newspaper/ magazine and a smartphone app

New York Times Magazine QR code cover (Pavlik \& Bridges 2013)

Esquire magazine $\mathrm{AR}$ issue (Esquire magazine 2009)

Time magazine Optimism issue (Bosworth \& Sarah 2018)

New York Times: Statue of Liberty (Stapinski 2018)

New York Times: Four of the Best Olympians

(Branch 2018)

ABC: Space Discovery (Bazley 2018)
A story with virtual objects superimposed on the user's environment

Smartphone app

Anywhere
Washington Post: Freddie
Gray's case
(WashPostPR 2016)


TABLE 13.2 (Cont.)

\begin{tabular}{|c|c|c|c|}
\hline Type of AR storytelling & Platforms/devices used & $\begin{array}{l}\text { Physical } \\
\text { environment }\end{array}$ & Examples \\
\hline $\begin{array}{l}\text { News video inside } \\
\text { augmented reality }\end{array}$ & AR glasses & Anywhere & $\begin{array}{l}\text { CNN app in Magic Leap } \\
\text { (Roettgers 2019) } \\
\text { Cheddar app in Magic } \\
\text { Leap (Strange 2018) }\end{array}$ \\
\hline $\mathrm{AR}$ as a reporting tool & & & $\begin{array}{l}\text { Hindustan Times: Using } \\
\text { Snapchat filters } \\
\text { for anonymizing } \\
\text { interviewees (Scott } \\
\text { 2016) }\end{array}$ \\
\hline
\end{tabular}

According to our findings, the main implications of AR for journalism can be seen in smartphone apps and TV broadcasts. As smartphones have become ubiquitous and mobile AR technology is developing, content providers can easily reach a vast number of users all over the world: there were about 990 million ARKit- and ARCore-compatible smartphones at the end of 2018, with 129 million monthly active users (Boland 2018). The same report predicts that these numbers will double in 2019. When compared to the problem of the low penetration percentage of VR gadgets like HMDs in the mass market, AR will soon be available for all smartphone users.

At the turn of the 2020s, we argue that the most powerful AR experiences so far have been focused on weather predictions, especially by The Weather Channel, and live sports events. As climate change has become one of the most urgent news topics of our times, it is easy to predict that other news producers, especially those with a decent budget for testing new technologies and innovations, will probably follow suit. The big sports broadcasters have also always been at the forefront of journalistic innovations globally due to their enormous budgets and intensive competition.

Over the last ten years, the potential of AR for storytelling and journalism has grown. However, as our interviewee mentioned at the start of this chapter, it remains to be seen when the use of AR will be as ubiquitous as smartphones are nowadays.

\section{References}

110stories. 2019."110stories: Harnessing the storytelling power of immersive mobile media." 110stories, April. www.110stories.com/ [Accessed 15 March 2020].

ABC News. 2018. "The royal wedding augmented reality experience." ABC News, 12 December. https://abcnews.go.com/US/royal-wedding-augmented-reality-experience/ story?id=59750374 [Accessed 15 March 2020].

Allum, Cynthia, Elyssa Goldberg, Matthew Weinberg, Rashmi Bhagwat, \& Siddharth Shanbhag. 2018. "The state of augmented reality." NYC Media Lab/RYOT Studio white paper. www.ryotstudio.com/whitepaper/RYOTStudio-CBS-AR-WhitePaper.pdf [Accessed 15 March 2020]. 
Augment.com. 2016. "Did sports pave the way for augmented reality?" 7 July. www.augment. com/blog/sports-pave-way-augmented-reality/ [Accessed 15 March 2020].

Azuma, Ronald. 1997. "A survey of augmented reality." Presence: Teleoperators and Virtual Environments 6(4), August: 355-385.

Azuma, Ronald. 2015. "Location-based mixed and augmented reality storytelling" In: Woodrow Barfield (ed.), Fundamentals of Wearable Computers and Augmented Reality. Boca Raton, FL: CRC Press, pp. 259-276.

Baluja,Tamara. 2013. "Augmented reality: The latest fad for newspapers or a real innovation?" J-Source.ca. https://j-source.ca/article/augmented-reality-the-latest-fad-for-newspapersor-a-real-innovation/ [Accessed 15 March 2020].

Bazley, Nathan. 2018. "Backstory: Exploring the potential of augmented reality with the launch of Space Discovery app." ABC Backstory, 22 May. www.abc.net.au/news/about/ backstory/digital/2018-05-22/making-ar-space-discovery/9786402 [Accessed 15 March 2020].

Beech, Hannah. 2018. "Step Inside the Thai Cave in Augmented Reality." The New York Times, 21 July. www.nytimes.com/interactive/2018/07/21/world/asia/thai-cave-rescuear-ul.html [Accessed 15 March 2020].

Berryman, Donna R. 2012. “Augmented reality: A review.” Medical Reference Services Quarterly 31(2), May: 212-218.

Billinghurst, Mark, Hirokazu Kato, \& Ivan Poupyrev. 2001. "The MagicBook: a transitional AR interface." Computers \& Graphics 25(5), October: 745-753.

Bohn, Dieter. 2019. "Microsoft's HoloLens 2: A $\$ 3,500$ mixed reality headset for the factory, not the living room." The Verge, 24 February. www.theverge.com/2019/2/24/18235460/ microsoft-hololens-2-price-specs-mixed-reality-ar-vr-business-work-features-mwc2019 [Accessed 15 March 2020].

Boland, Mike. 2018. "990 Million ARKit \& ARCore Smartphones in the Wild.” AR Insider. 27 December. https://arinsider.co/2018/12/27/990-million-arkit-arcore-smartphonesin-the-wild/ [Accessed 15 March 2020].

Bosworth, Melissa \& Lakshmi Sarah. 2018. Crafting Stories for Virtual Reality. Abingdon-onThames, UK: Routledge.

Branch, John. 2018. "Four of the best Olympians, as you've never seen them." The New York Times. 5 February. www.nytimes.com/interactive/2018/02/05/sports/olympics/araugmented-reality-olympic-athletes-ul.html [Accessed 15 March 2020].

Cappucci, Matthew. 2018. "Watch a virtual tornado demolish the Weather Channel studio." The Washington Post, 20 June. www.washingtonpost.com/news/capital-weather-gang/ wp/2018/06/20/watch-a-virtual-tornado-demolish-the-weather-channel-studio/ ?noredirect $=$ on\&utm_term $=.374 \mathrm{dca3}$ ef796 [Accessed 15 March 2020].

Caudell, Thomas P. \& David W. Mizell. 1992. "Augmented reality: An application of headsup display technology to manual manufacturing processes." 1992 Hawaii International Conference on System Sciences (HICSS'92). 7-10 January, Hawaii. https://doi.org/10.1109/ HICSS.1992.183317

Cave, Andrew. 2015. “Why Google Glass flopped.” Forbes.com, 20 January 2015. www.forbes. com/sites/andrewcave/2015/01/20/a-failure-of-leadership-or-design-why-googleglass-flopped/\#6182120057ff [Accessed 15 March 2020].

Chaudhary, Apurva. 2012. "Times of India launches another augmented reality app: Times alive." Medianama, 18 December. www.medianama.com/2012/12/223-times-of-indialaunches-another-augmented-reality-app-times-alive/ [Accessed 15 March 2020].

CNN. 2018. "Enter a new dimension: Will.i.am's augmented reality revolution." CNN Style, 8 November. https://edition.cnn.com/style/article/will-i-am-black-eyed-peas-mastersof-the-sun-smart-creativity/index.html [Accessed 15 March 2020]. 
Dirin, Amir \& Teemu H. Laine. 2018. "User experience in mobile augmented reality: Emotions, challenges, opportunities and best practices." Computers 7(2), May.

Egripment. 2018. "CNN's Super Bowl Special uses Egripment's augmented reality system." Egripment, February. https://egripment.com/news/cnn\%E2\%80\%99s-super-bowlspecial-uses-egripment $\%$ E2\%80\%99s-augmented-reality-system/ [Accessed 15 March 2020].

eMacula. 2019. “The world's first human friendly full field of view AR/VR system.” eMacula, 16 April. www.emacula.io/ [Accessed 15 March 2020].

Emrich, Tom. 2013. "The Toronto Star uses augmented reality to try to go beyond the ink." Betakit, 19 September. https://betakit.com/the-toronto-star-uses-augmented-reality-totry-to-go-beyond-the-ink/ [Accessed 15 March 2020].

Esquire. 2009. "Behind the scenes of augmented Esquire." Esquire magazine, 9 November. www.esquire.com/news-politics/news/g371/augmented-reality-technology-110909/ ?slide $=10$ [Accessed 15 March 2020].

Fedorovskaya, Elena \& Lufei Yu. 2015. "Investigating the effects of publishing approaches using print, electronic and augmented reality media on user experience." Journal of Print and Media Technology Research 4(3), September: 217-226.

Feiner, Steven K. 2002. "Augmented reality: A new way of seeing.” Scientific American 286(4), April: 48-55.

Goyal, Gaurav. 2016. "This 15th August, introducing augmented reality in Jaipur's Dainik Bhaskar with Yeppar.” Medium.com,10 August. https://medium.com/@yeppar/this15th-august-introducing-augmented-reality-in-jaipurs-dainik-bhaskar-with-yeppar254264a25a1 [Accessed 15 March 2020].

The Guardian. 2012. "Guardian partners with Blippar for augmented reality ad and editorial." The Guardian, 20 April. www.theguardian.com/gnm-press-office/guardian-partnerswith-blippar [Accessed 15 March 2020].

Hamilton Spectator. 2016. "The Dolphin Way." Hamilton Spectator, 11 July. www.thespec.com/ community-story/6761980-the-dolphin-way/ [Accessed 15 March 2020].

Hannaford, Kat. 2009. "Stella Artois uses augmented reality in cool iPhone app." Gizmodo, 21 December. https://gizmodo.com/stella-artois-uses-augmented-reality-incool-iphone-app-5431120 [Accessed 15 March 2020].

Hauser, Andreas. 2010. "Wikitude world browser." Wikitude.com, 9 August 2010. www. wikitude.com/wikitude-world-browser-augmented-reality/ [Accessed 15 March 2020].

Heaney, David. 2019. "Report: Facebook's upcoming AR glasses much less bulky than hololens or magic leap." Upload VR, 18 January. https://uploadvr.com/facebook-arglasses-abrash-report/ [Accessed 15 March 2020].

Hill, Michael P. 2018a. "Al Jazeera English uses AR to map out Holy Land." Newscast Studio, 26 January. www.newscaststudio.com/2018/01/26/holy-land-augmentedreality/ [Accessed 15 March 2020].

Hill, Michael P. 2018b. "Augmented reality helps Al Jazeera explain Winter Olympics sports." NewscastStudio, 21 February. www.newscaststudio.com/2018/02/21/al-jazeeraaugmented-reality-olympics-2018/ [Accessed 15 March 2020].

Höllerer, Tobias, Steven Feiner, \& John Pavlik. 1999. "Situated documentaries: Embedding multimedia presentations in the real world." Paper presented at the Third International Symposium on Wearable Computers, San Francisco, CA, USA, 18-19 October. https:// ieeexplore.ieee.org/abstract/document/806664 [Accessed 15 March 2020].

Jacobson, Lindsey. 2018. "Behind the scenes on Election Day: 360-degree video of the ABC News election set and AR experience." $A B C$ News, 5 November. https://abcnews. go.com/Politics/scenes-election-day-360-degree-video-abc-news/story?id=58942385 [Accessed 15 March 2020]. 
Kieslow, Damon. 2011. "Boston Globe's augmented reality project an example of quick, cheap innovation.” Poynter newsletter. 9 February. www.poynter.org/newsletters/2011/ boston-globes-augmented-reality-project-an-example-of-quick-cheap-innovation/ [Accessed 15 March 2020].

Kipper, Greg \& Joseph Rampolla. 2013. Augmented reality: An emerging technologies guide to AR. Amsterdam; Boston, MA: Syngress/Elsevier.

Knight Foundation. 2018. "Journalism 360 awards $\$ 195,000$ to 11 winning projects that use immersive storytelling to advance journalism.” Knight Foundation press release, 12 September. www.knightfoundation.org/press/releases/journalism-360-awards-195000-to-11-winning-projects-that-use-immersive-storytelling-to-advance-journalism [Accessed 15 March 2020].

Ko, Sang M., Won S. Chang, \& Ji Yong G. 2013. “Usability principles for augmented reality applications in a smartphone environment." International Journal of Human-Computer Interaction 29(8), August: 501-515.

Kothari, Jay. 2017. “A new chapter for Glass.” Medium.com, 18 July. https://blog.x.company/ a-new-chapter-for-glass-c7875d40bf24 [Accessed 15 March 2020].

Kunova, Marcela. 2019."Pros and cons of using augmented reality in the newsroom." Journalism. co.uk, 8 May. www.journalism.co.uk/news/pros-and-cons-of-using-augmented-reality-inthe-newsroom/s2/a738521/ [Accessed 15 March 2020].

LaForme, Ren. 2018. "The Weather Channel created a tornado that tore down their walls." Poynter Tech \& Tools, 26 June. www.poynter.org/tech-tools/2018/the-weatherchannel-created-a-tornado-that-tore-down-their-walls/ [Accessed 15 March 2020].

Langley, Hugh. 2018. "The patented history and future of... Google Glass: Quite the spectacle." Wareable, 7 April. www.wareable.com/features/the-patented-history-and-futureof-google-glass-656 [Accessed 15 March 2020].

Layar. 2013. "Glacier Media launches massive interactive print rollout with Layar." layar.com, 7 February. www.layar.com/news/press-releases/glacier-media/ [Accessed 15 March 2020].

Lemley, Mark A. \& Eugene Volokh. 2017. "Law, virtual reality, and augmented reality." University of Pennsylvania Law Review 166: 1051-1138.

Levy, Stephen. 2017. "Google Glass 2.0 Is a startling second act." Wired.com, 18 July. www. wired.com/story/google-glass-2-is-here/ [Accessed 15 March 2020].

Mahpar, M. Hafidz \& Eugene Mahalingam. 2012. "iSnap feature excites media specialist companies." The Star Online, 28 April. www.thestar.com.my/business/business-news/2012/ 04/28/isnap-feature-excites-media-specialist-companies/ [Accessed 15 March 2020].

Mann, Steve, John C. Havens, Jay Iorio, Yu Yuan, \& Tom Furness. 2018. "All reality: Values, taxonomy, and continuum, for Virtual, Augmented, eXtended/MiXed (X), Mediated (X, Y), and Multimediated Reality/Intelligence." Paper Presented at AWE 2018, Santa Clara, California, USA, 31 May.

Milgram, Paul \& Fumio Kishino. 1994. "A taxonomy of mixed reality visual displays." IEICE TRANSACTIONS on Information and Systems 77(12), December: 1321-1329.

Moses, Lucia. 2017. “The Washington Post is diving into augmented reality.” Digiday UK, 15 May. https://digiday.com/media/washington-post-diving-augmented-reality/ [Accessed 15 March 2020].

The New York Times. 2019. "Your guide to augmented reality in The Times." The New York Times, 17 April. www.nytimes.com/interactive/2018/02/01/sports/olympics/nyt-araugmented-reality-guide.html [Accessed 15 March 2020].

Newman, Nic. 2018. Journalism, Media and Technology Trends and Predictions 2018. Oxford, UK: Reuters Institute for the Study of Journalism, Oxford University. https:// reutersinstitute.politics.ox.ac.uk/our-research/journalism-media-and-technologytrends-and-predictions-2018 [Accessed 15 March 2020]. 
O'Hear, Steve. 2010. "Video: The 'first' dead tree magazine with Augmented Reality support." TechCrunch, 19 August. https://techcrunch.com/2010/08/19/video-the-firstdead-tree-magazine-with-augmented-reality-support/?guccounter=1 [Accessed 15 March 2020].

Pahwa, Nikhil. 2010. "Mid Day introduces QR codes for rich content via mobile." Medianama, 18 February. www.medianama.com/2010/02/223-mid-day-introduces-qrcodes-for-rich-content-via-mobile/ [Accessed 15 March 2020].

Pavlik, John V. \& Frank Bridges. 2013. "The emergence of augmented reality (AR) as a storytelling medium in journalism." Journalism and Communication Monographs 15(1), January: $4-59$.

Press Gazette. 2013. "Independent claims world first as it uses 'augmented reality' app to enhance daily print content." Press Gazette, 23 April. www.pressgazette.co.uk/ independent-claims-world-first-as-it-uses-augmented-reality-app-to-enhance-dailyprint-content [Accessed 15 March 2020].

Radcliffe, Damian, Christopher Ali, \& Rosalind Donald. 2017. "Life at small-market newspapers: Results from a survey of small market newsrooms." Columbia University Academic Commons, 16 May. https://academiccommons.columbia.edu/doi/10.7916/ D8XP7BGC [Accessed 15 March 2020].

Raso, Rocco, Sebastian Cucerca, Dirk Werth, \& Peter Loos. 2016. “Automated augmented reality content creation for print media.” In: A. Lugmayr, E. Stojmenova, K. Stanoevska, \& R. Wellington (eds), Information Systems and Management in Media and Entertainment Industries. International Series on Computer Entertainment and Media Technology. Cham, Switzerland: Springer.

Roettgers, Janko. 2019. "CNN launches app on Magic Leap One headset." Variety, 28 February. https://variety.com/2019/digital/news/cnn-magic-leap-one-app1203151975/ [Accessed 15 March 2020].

Royakkers, Lamber, Jelte Timmer, Linda Kool, \& Rinie van Est. 2018. "Societal and ethical issues of digitization." Ethics and Information Technology 20(2), March: 127-142.

Schmalstieg, Dieter, Tobias Langlotz, \& Mark Billinghurst. 2011. "Augmented Reality 2.0.” In: G. Brunnett, S. Coquillart, \& G. Welch (eds), Virtual Realities. Vienna: Springer.

Scott, Caroline. 2016. "Hindustan Times uses Snapchat filters to enable sexual assault survivors to speak freely on camera." Journalism.co.uk, 11 July. www.journalism.co.uk/ news/using-snapchat-s-filters-to-conceal-interviewee-identities/s2/a654554/ [Accessed 15 March 2020].

Siriborvornratanakul, Thitirat. 2018. "Enhancing user experiences of mobile-based augmented reality via spatial augmented reality: Designs and architectures of projectorcamera devices." Advances in Multimedia, April: 1-17.

Southern, Lucinda. 2017. "Quartz adds augmented reality to its app, now with 780k downloads." Digiday UK, 9 October. https://digiday.com/media/quartz-findsaugmented-reality-drives-app-downloads/ [Accessed 15 March 2020].

Spark AR. 2018. Spark AR website. https://sparkar.facebook.com/ [Accessed 15 March 2020].

Stapinski, Helene. 2018. "Take a tour of Lady Liberty's torch (right this second)." The New York Times, 13 November. www.nytimes.com/interactive/2018/11/13/nyregion/ statue-of-liberty-torch-ar-ul.html?action $=$ click\&module $=$ RelatedLinks\&pgtype $=$ Article [Accessed 15 March 2020].

Statt, Nick. 2019. "These slick new AR glasses project shockingly high-quality visuals." The Verge, 9 January. www.theverge.com/circuitbreaker/2019/1/9/18176083/nrealaugmented-reality-ar-smart-glasses-features-pricing-release-date-ces-2019 [Accessed 15 March 2020]. 
Strange, Adario. 2018. "Magic Leap launches Cheddar Video news channel on Magic Leap One.” Magic Leap News, 12 December. https://magic-leap.reality.news/news/magicleap-launches-cheddar-video-news-channel-magic-leap-one-0191260/ [Accessed 15 March 2020].

Sutherland, Ivan. 1965. “The ultimate display.” In: Proceedings of the IFIP Congress, pp. 506-508.

Swider, Matt \& Michelle Fitzsimmons. 2019. "Magic Leap One release date, price and features." Techradar, 4 January. www.techradar.com/news/magic-leap-one [Accessed 15 March 2020].

Väätäjä, Heli K., Mari J.Ahvenainen, Markus S. Jaakola, \& Thomas D. Olsson. 2013.“Exploring augmented reality for user-generated hyperlocal news content." Paper presented at CHI'13 Extended Abstracts on Human Factors in Computing Systems, Paris, 27 April. https://doi.org/10.1145/2468356.2468529 [Accessed 15 March 2020].

Valcarce, David. P., Concha E. Bolós, \& Juan C.M. Recio. 2017. "Analysis of the application of augmented reality technologies in Spanish mass media productive processes." Revista Latina De Comunicación Social 72: 1670-1688.

WashPostPR. 2016. “The Washington Post releases augmented reality view of Freddie Gray's case." The Washington Post PR blog, 10 May. www.washingtonpost.com/pr/wp/2016/ 05/10/the-washington-post-releases-augmented-reality-view-of-freddie-grays-case / [Accessed 15 March 2020].

Wassom, Brian. 2014. Augmented reality law, privacy, and ethics: Law, society, and emerging AR technologies. Waltham, MA: Syngress.

Witkin, Kira. 2013. "Independent integrates augmented reality into editorial workflow." WAN-IFRA blog, 26 April. https://blog.wan-ifra.org/2013/04/26/independentintegrates-augmented-reality-into-editorial-workflow [Accessed 15 March 2020].

Wolf, Marty J., Frances Grodzinsky, \& Keith Miller. 2016. "Augmented reality all around us: Power and perception at a crossroads." ACM SIGCAS Computers and Society 45(3): 126-131.

Zhou, Tao. 2018. "Examining user adoption of mobile augmented reality applications." International Journal of E-Adoption (IJEA) 10(2), July: 37-49. 